\title{
Surgery 2019: an existential crisis
}

\author{
Marco G. Patti ${ }^{1,2} \cdot$ Melina R. Kibbe ${ }^{2,3}$
}

Received: 7 June 2019 / Accepted: 14 June 2019 / Published online: 21 June 2019

(C) Italian Society of Surgery (SIC) 2019

Confucius (551 BC-479 BC) was a Chinese teacher, politician, and philosopher of the Spring and Autumn period of Chinese history. One of his most famous quotes reads: "Choose a job you love, and you will never have to work a day in your life". We fully agree with this quote. Like anybody else, we had some challenging moments during medical school, residency and later in our academic career, but we overcame those moments and adjusted to an ever changing environment, without losing the love for our work, the desire to help others along the same path we chose, and the goal of caring for our patients. Decades after completing medical school we still feel in the same way, and we do consider it an honor and a privilege to be a surgeon.

The Problem-Burnout: unfortunately, today the world of medicine in general, and of surgery in particular, is faced with a problem that is affecting medical students, residents and practicing physicians: burnout [1]. In 2014, Elmore et al. performed a national survey of burnout among US general surgery residents. Burnout was assessed using the Maslach Burnout Inventory, evaluating scores for three subscales: emotional exhaustion, depersonalization, and personal accomplishment [1]. Sixty-nine percent of residents met the criteria for burnout in at least one scale: rates of burnout were higher in residents planning a career in private practice, among women, and correlated with greater work hours per week. Burnout, however, is not limited to trainees only, but is also present among practicing surgeons. In 2008, a survey of the American College of Surgeons showed very high rates of burnout among its members, and identified the

Marco G. Patti

marco_patti@med.unc.edu

1 Department of Medicine, University of North Carolina at Chapel Hill, 4030 Burnett Womack Building, 101 Manning Drive, CB 7081, Chapel Hill, NC 27599-7081, USA

2 Department of Surgery, University of North Carolina at Chapel Hill, Chapel Hill, NC, USA

3 Department of Biomedical Engineering, University of North Carolina at Chapel Hill, Chapel Hill, NC, USA following potential causes for this finding: younger age, having children, area of specialization (trauma surgeons were affected more often), number of nights on call per week, work-home conflicts, and compensation [2]. In addition, the need to be current with new and important information and regulations, the electronic medical record, evolving technology, patients' increased expectations of care, and legal concerns (i.e., fear of litigation) were also thought to play a role. In a follow-up survey of 7,905 surgeons funded by the American College of Surgeons, Shanafelt and colleagues found that $6 \%$ reported some element of suicidal ideation during the prior 12 months, albeit only $26 \%$ sought psychiatric care for the fear of compromising their medical license [3]. Most recently, in 2018 a survey of 6 general surgery training programs in North Carolina revealed an incidence of burnout among residents and faculty of $75 \%$, with $39 \%$ of those meeting the definition for depression [4]. A very concerning aspect of the data is that $12 \%$ reported having suicidal ideation in the prior 2 weeks. Barriers to seeking care for burnout included the inability to take time off to seek treatment, avoidance or denial of the problem, and the perception of a negative stigma associated with seeking care. As a consequence of this burnout, many surgeons would not recommend a career in surgery to their own children, further hurting the reputation of our profession [3].

During the last 20 years, fewer US medical students are choosing a career in surgery and the ranks have been filled by international medical graduates. Today $25 \%$ of residency positions in general surgery programs are filled by individuals who have completed medical school outside the United States. The cause of this crisis of the surgical profession in the United States is clearly multifactorial and its solution is not easy. The following are some factors that probably play a role.

Generational gap: most of the work force today is composed by members of generations X (1960-1980) and Y (1981-2000), with the millennials making up the medical student and resident class. While members of the Baby Boom generation (1946-1959) were goal oriented, loyal to the institution, respectful of a hierarchical system, and 
motivated to succeed, for members of generation $\mathrm{X}$ and $\mathrm{Y}$ the achievement of a balance between work and life, between personal and professional life, is the main goal. However, achieving this balance is perceived as more challenging in surgery due to the nature of the profession (long hours in the operating room, physical demands, longer training period, less autonomy, etc.), and the increasing stress on productivity with less time available for education and scholarship. The changes in priorities of medical students have been well documented in a study of 1,365 students by Sanfey et al. [5]. While in the 1980s life style and personal factors were considered the least important in making a career choice, today family and lifestyle are the priorities that influence career choices for most women and men, suggesting that generational changes play a major role. As family life is particularly important for women, the declining interest in surgery could be in part explained by the increased number of women in medical schools [5].

While we do acknowledge these concerns, we believe that it is all about choices: if somebody wants to be a successful academic surgeon, excelling clinically and in research and education, he or she has to recognize that there will tradeoffs between career and time left for family activities or hobbies. On the other hand, if the goal is to have a fulfilling family life, a compromise must be made in terms of professional goals. Regardless, it is important to understand that choices must be made. Further, it is important to realize that choices may evolve over time; choices made today may not be the right choices for the future. Changes and adjustments to work-life choices can and should be made with the passage of time.

Impact of medical school experience: unfortunately medical students witness every day the change in the educational environment, and are exposed to individuals who express frustration and displeasure for their career choices. They witness the attrition from surgery residency programs, mostly by interns or second year residents who feel that they were not adequately prepared for and informed about the rigor of a residency in surgery [6]. In addition, mistreatment of the medical students often occurs during surgery clerkship rotations, and this has a downstream effect on mental health, job satisfaction, and career choices. Medical students often feel that they are not integrated into the surgical team and feel a negative attitude of the residents towards them. For instance, due to the change in work hours established in 2003 with a limit of $80 \mathrm{~h} /$ week, the old concept of evening rounds conducted by the chief residents with the goal of educating junior residents and medical students has largely disappeared and has been replaced by "working rounds", often sitting around a table in order to sign off to the evening person on call.

The future: being faced with this crisis, we recommend the adoption of the following principles in order to address and improve burnout, and support the profession of surgery as a career choice.

Acceptance of the generational changes: we must acknowledge the passage of time and the changes that have occurred at the beginning of the twenty-first century at a national and global level in science, healthcare, surgical education, and practice. We must acknowledge the characteristics of each generation, accepting them for who they are, and treasuring the contribution that they can make. We need to accept generational changes as a form of evolution, and not as a different and wrong way to be a surgeon.

Clarify expectations: changes must be made to improve the experience of medical students during the surgery clerkship. Medical students must have clear expectations about their role in the team, reading about the different diseases, knowing the patients they are assigned, accepting questions not as a form of humiliation but as a way to improve their fund of knowledge, and being willing to help the residents with patient management. Residents must realize that their role is very important, from making the medical students feeling welcome on the team to teaching them in a nonconfrontational manner. Attending surgeons must focus on teaching during clinics and in the operating room, from anatomy to physiology, from work-up of disease processes to technical aspects of the operation to postoperative care. If these expectations are clarified up front, there would be fewer incidents of mistreatment and greater alignment among the team, leading to greater satisfaction for all.

Actively provide mentorship: a recent study showed that only half of departments of surgery in the United States have established mentorship programs for faculty and that, among those who have them, the structure varies significantly [7]. This creates a downstream effect as unhappy faculty will transmit their frustration to residents and medical students and not serve as good role models to either. The current crisis also shows the need of early intervention with a structured mentorship program in the medical school curriculum, as this could counteract the decline in the number of students interested in pursuing a career in surgery. One-on-one time with surgeons during rounds, in didactics, in clinics, and first assisting in the operating room would enhance their experience being exposed to the real world of surgery. As residents spend the greatest amount of time with medical students on a daily basis, they should be taught how to function as mentors and role models, realizing the impact that their words, actions, and attitudes have on medical students.

In conclusion, it is clear that surgery as a profession is becoming an existential crisis. As the rates of burnout have reached unprecedented highs, we must enact changes in order to preserve the joy, honor, and privilege of our profession. We must accept generational changes for what they are, and adapt our practices accordingly to meet the needs of the new generations. We must set expectations up front, so as to 
minimize misunderstandings and enhance the experience of medical students rotating on surgery, and continually serve as mentors and role models to others. As stressed by Dr. Haile Debas in his Presidential talk at the American Surgical Association [8]: "surgery is a noble profession in a changing world, a profession imbued with eminence, dignity, high ideals, ethical values and a rich and proud heritage. In order to retain its attractiveness as a career choice for students, surgery must evolve with the times".

\section{Compliance with ethical standards}

Conflict of interest The authors have no conflict of interest to declare.

Research involving human participants and/or animals This article does not contain any studies with human participants or animals performed by any of the authors.

Informed consent For this type of study, formal consent is not required.
2. Shanafelt TD, Balch CM, Bechamps GJ et al (2009) Burnout and career satisfaction among American surgeons. Ann Surg 250:463-471

3. Shanafelt TD, Balch CM, Dyrbye L et al (2011) Special report: suicidal ideation among American surgeons. Arch Surg 146:54-62

4. Williford ML, Scarlet S, Meyers MO, Luckett DJ, Fine JP, Goettler CE, Green JM, Clancy TV, Hildreth AN, Meltzer-Brody SE, Farrell TM (2018) Multiple-institution comparison of resident and faculty perceptions of burnout and depression during surgical training. JAMA Surg 153(8):705-711

5. Sanfey HA, Saalwachter-Schulman AR, Nyhof-Young JM et al (2006) Influences on medical students career choices. Gender or generation? Arch Surg. 141:1086-1094

6. Symer MM, Abelson JS, Wong NZ et al (2018) Impact of medical school experience on attrition from general surgery residency. J Surg Res 232:7-14

7. Kibbe MR, Pellegrini CA, Townsend CM, Helenowski IB, Patti MG (2016) Characterization of mentorship programs in departments of surgery in the United States. JAMA Surg 15:900-906

8. Debas HT (2002) Surgery: a noble profession in a changing world. Ann Surg 236:263-269

Publisher's Note Springer Nature remains neutral with regard to jurisdictional claims in published maps and institutional affiliations.

\section{References}

1. Maslach C, Jackson SE (1981) The measurement of experienced burnout. J Occup Behav 2:99-113 